\title{
PAPER
}

\section{Excess attenuation of road traffic noise by detached houses: Predictions when receiving points are lower than houses}

\author{
Kazutoshi Fujimoto*, Ken Anai ${ }^{\dagger}$ and Ryusei Ohta ${ }^{\ddagger}, \S$ \\ Faculty of Human-Environment Studies, Kyushu University \\ (Received 26 July 2002, Accepted for publication 19 November 2002)
}

\begin{abstract}
The purpose of this paper is to present a simple method for predicting the excess attenuation of road traffic noise by detached houses. The Acoustical Society of Japan (ASJ) presents one method; however, it cannot estimate noise levels at specific individual points in residential areas. In this paper, therefore, an experiment is performed with a one-twentieth scale model and a new empirical formula for excess attenuation, based on only five parameters, is proposed. The validity of the formula is verified through additional experiments, a comparison with the current method, and noise measurements in actual residential areas. This new and simple method is applicable to evaluations of environmental quality standards for noise.
\end{abstract}

Keywords: Excess attenuation, Noise propagation, Model experiment, Road traffic noise

PACS number: $43.50 . \mathrm{Rq}$

\section{INTRODUCTION}

Since Japan is a small country, residential areas often adjoin arterial roads. The residential buildings in these areas are seriously affected by road traffic noise, and a countermeasure to this noise must be found and implemented as soon as possible. For this purpose, the Ministry of Environment in Japan revised the 'Environmental Quality Standards for Noise' [1] in 1999 and has been enforcing it. The problem of environmental noise in areas facing roads is evaluated by obtaining the numbers and the rates of the buildings at which noise levels exceed the environmental quality standards. The standards allow for the estimation of noise levels, instead of requiring actual measurements, in cases where taking the actual measurements would be difficult. In order to estimate noise levels, it is necessary to grasp the excess attenuation by the buildings. However, it is very difficult to rigorously deal with noise propagation in residential areas where more than one complex-shaped building is located. Uesaka et al. [2] introduced a method of estimating 'average' noise levels behind buildings. It was adopted into the Acoustical Society of Japan's 1998 Prediction Model for Road Traffic Noise (ASJ Model 1998) [3]. In addition to this, the prediction of noise attenuation at 'specific points' and the

*e-mail: fujimoto@arch.kyushu-u.ac.jp

†e-mail: anai@arch.kyushu-u.ac.jp

‡e-mail: ryusei.ohta@accenture.com

${ }^{\S}$ Present address: Accenture Corporation estimation of the distribution of noise levels in residential areas are both significant and effective for evaluating actual environments.

Considering the above information, the authors [4,5] previously presented a method for predicting the excess attenuation by detached houses in residential areas at arbitrary points which have a height of $1.2 \mathrm{~m}$. In this paper, an extended prediction formula is proposed in which the height of the predicting points can be selected arbitrarily; however, it must be lower than the height of the houses.

\section{SCALE MODEL EXPERIMENT}

\subsection{Outline of the Experiment}

A one-twentieth scale model of a residential area, $100 \mathrm{~m} \times 80 \mathrm{~m}$ (original size), was set in a semi-anechoic chamber, as shown in Fig. 1. The sound pressure level $\left(L_{\mathrm{p}}\right)$ was measured at receiving points in the residential area as a model vehicle ran along a straight road $100 \mathrm{~m}$ in length. The excess attenuation of the road traffic noise by the detached houses was then calculated.

\subsection{Model Houses}

Each detached house was assumed to be a rectangular parallelepiped, $8 \mathrm{~m} \times 8 \mathrm{~m}$ or $8 \mathrm{~m} \times 16 \mathrm{~m}$ according to the ground plan and with a height of $4 \mathrm{~m}, 7 \mathrm{~m}$, or $10 \mathrm{~m}$, and was to be placed in the residential area at random. The model houses were prepared in four patterns of arrangements, and the ratios of the areas of the houses to the entire residential area (hereafter referred to as the 'covering percentages') 


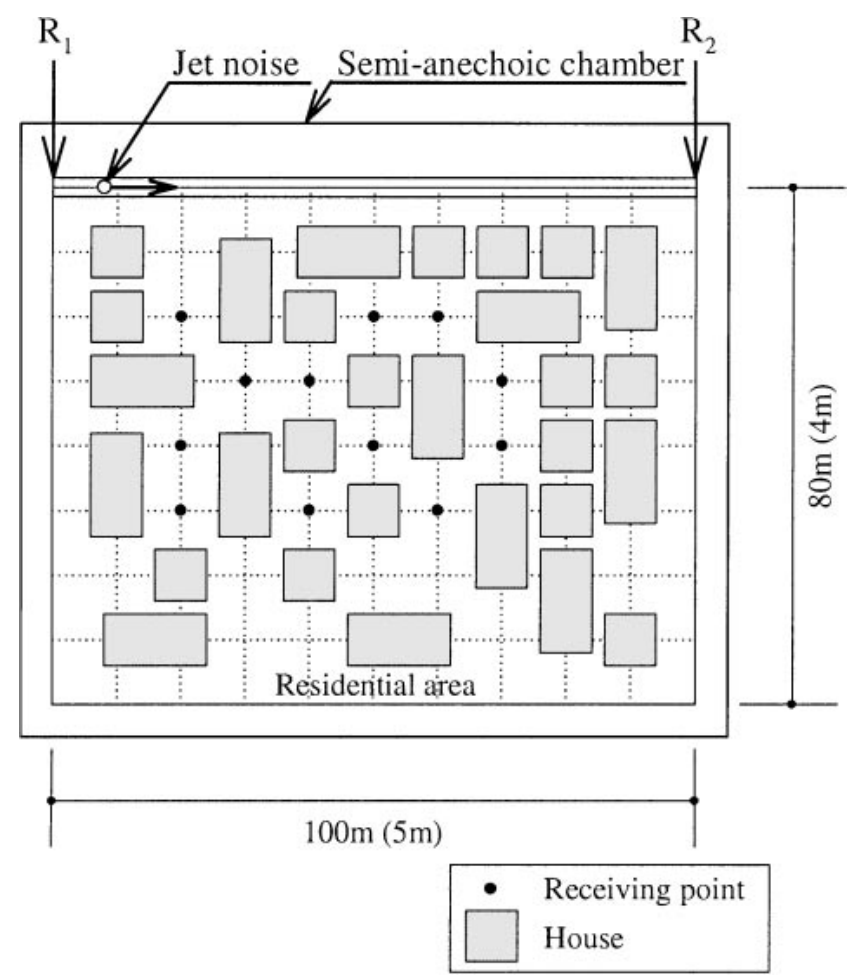

Fig. 1 Outline of the model experiment.

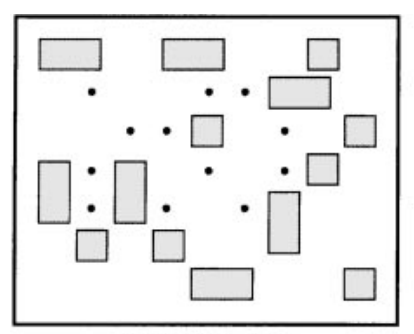

T-11, T-21, T-31

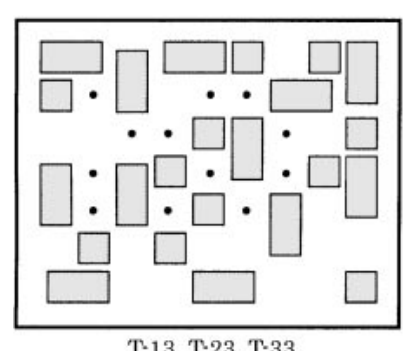

$\mathrm{T} \cdot 13, \mathrm{~T} \cdot 23, \mathrm{~T} \cdot 33$

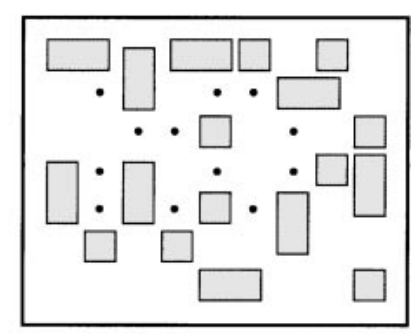

$\mathrm{T} \cdot 12, \mathrm{~T} \cdot 22, \mathrm{~T} \cdot 32$

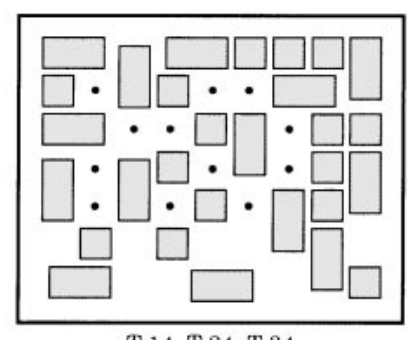

$\mathrm{T} \cdot 14, \mathrm{~T} \cdot 24, \mathrm{~T}-34$
Fig. 2 Arrangements of model houses.

were $16.8 \%, 21.6 \%, 28.0 \%$, and $34.4 \%$, as shown in Fig. 2. Here a symbol ' $\mathrm{T}-x y$ ' shows a pattern of arrangements of the model houses; $x=1,2$, and 3 for which $x$ is a number showing the height of the houses $(4,7$, and $10 \mathrm{~m}$ respectively) and $y=1,2,3$, and 4 is a number showing the pattern number of house arrangement. The model houses were made of polystyrene which was reflective of the frequency range of the measurements.

\subsection{Model Source and Receiving Points}

Jet noise was used as the model sound source. The

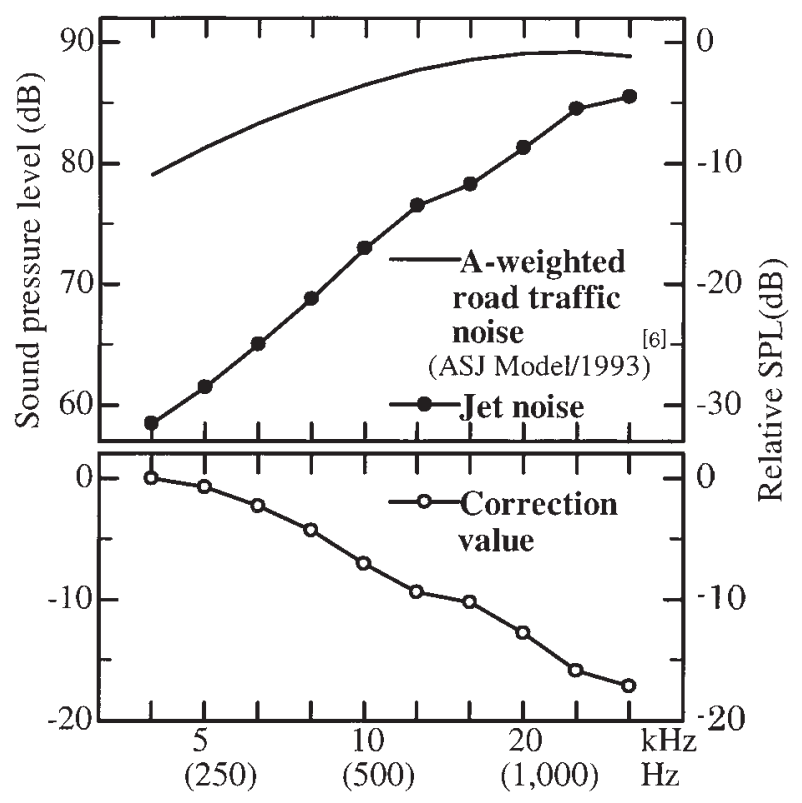

Fig. 3 Frequency characteristics of A-weighted road traffic noise and jet noise.

frequencies of it covered a range of $200 \mathrm{~Hz}$ to $1,600 \mathrm{~Hz}$ (original scale) for road traffic noise; and thus, it was considered to be an omni-directional point source for those frequencies. The height of the source was $0.5 \mathrm{~m}$ from the ground. The $L_{\mathrm{p}}$ was continuously measured while the source was moved at a constant speed from $R_{1}$ to $R_{2}$, as shown in Fig. 1. Assuming that the model source had a spectrum of road traffic noise [6], the measured $L_{\mathrm{p}}$ at each receiving point was converted into an A-weighted sound pressure level $\left(L_{\mathrm{pA}}\right)$ using a digital filter. The frequency characteristics of the source and the compensation values for the road traffic noise in the experiment are shown in Fig. 3.

The number of receiving points was twelve, as shown in Fig. 1. The perpendicular distances between the receiving points and the straight road $(d)$ were $20 \mathrm{~m}, 30 \mathrm{~m}, 40 \mathrm{~m}$, or $50 \mathrm{~m}$, while the height from the ground $\left(h_{\mathrm{p}}\right)$ was $1.2 \mathrm{~m}$, $5.2 \mathrm{~m}$, or $8.2 \mathrm{~m}$. As mentioned above, the height of all the receiving points here was lower than the height of the houses.

\subsection{Excess Attenuation}

The sound exposure level $\left(L_{\mathrm{AE}}\right)$ was calculated from the unit pattern that was time-changed from the noise level measured at the receiving point, while the source moved from one end $\left(\mathrm{R}_{1}\right)$ to the other $\left(\mathrm{R}_{2}\right)$ along the straight road. The excess attenuation by the houses $\left(\Delta L_{\mathrm{AE}}\right)$ was defined by the subtraction of $L_{\mathrm{AE}_{1}}$ from $L_{\mathrm{AE}_{0}}$, where $L_{\mathrm{AE}_{1}}$ and $L_{\mathrm{AE}_{0}}$ were the values of $L_{\mathrm{AE}}$ measured under the conditions that houses were placed and not placed, respectively. It should be noted that the excess attenuation defined here has a contrary meaning to the usual definition. 


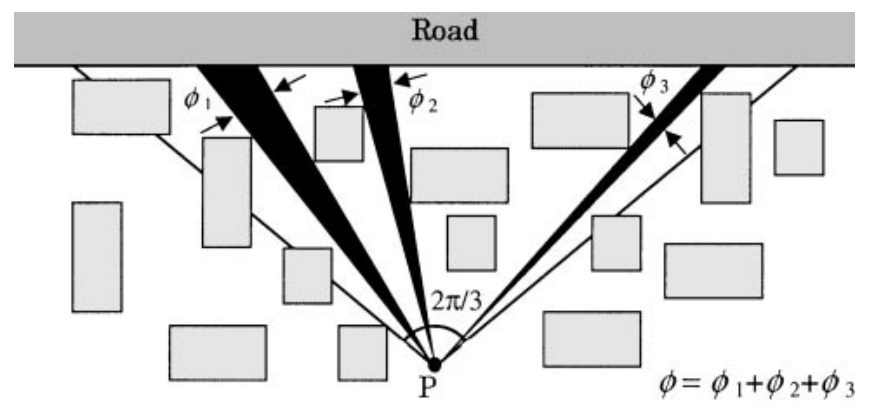

Fig. 4 Base triangle and open angle $\phi$.

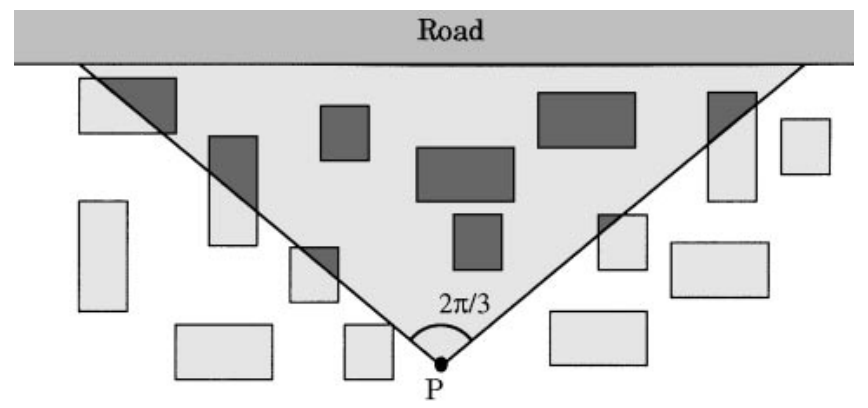

Fig. 5 Base triangle and house-occupied rate $\xi$.

\section{DERIVATION OF THE PREDICTION FORMULA}

\subsection{Parameters for the Prediction}

Since this study aims to find a simple method for predicting the excess attenuation of road traffic noise by detached houses, the following simple five parameters were introduced. Two of the parameters are based on an isosceles triangle with a vertex angle of $2 \pi / 3$ (hereafter referred to as a 'base triangle'), the vertex of which is the predicting point and the base side of which is the road, as shown in Figs. 4 and 5. The first of the two parameters is the summation of the angles determined by the roads that are visible from the receiving point, as shown in Fig. 4 (hereafter referred to as 'open angle' $\phi$ ). $\phi$ is $2 \pi / 3$ when no house is placed and zero when the road is not visible at all. The second of the two parameters is the rate of the total housing area in the base triangle to the base triangle area, as shown in Fig. 5 (hereafter referred to as 'house-occupied rate' $\xi$ ). These two parameters were introduced to understand the influence of direct sound and the obstruction of noise propagation by the houses in the path from the sound source to the receiving points. The other three parameters are the distances between the receiving points and the road $(d)$, the height of houses $(H)$, and the height of the receiving points $\left(h_{\mathrm{p}}\right)$.

If a receiving point is higher than a house, a case which is encountered when the road is visible over the house from the receiving point, the above-defined $\xi$ may be unable to present an exact open angle. In this research, therefore, the height of the receiving points is limited to being lower than the height of the houses.

\subsection{Relation between $\Delta L_{\mathrm{AE}}$ and $\phi$ or $\xi$}

Since excess attenuation is not affected so much by houses when the road is visible $[4,5]$, the relation between $\Delta L_{\mathrm{AE}}$ and $\phi$ was firstly examined when $\phi$ was not zero. The results are shown in Fig. 6, in which the dots are experimental values and a solid line shows the regression curve obtained by the least square method. This figure shows only some results when $H=10 \mathrm{~m}$ and $h_{\mathrm{p}}=1.2 \mathrm{~m}$ due to limitation of space. Careful observation of all the results, however, shows that $\Delta L_{\mathrm{AE}}$ decreases as $\phi$ decreases, and its relation depends on $H, h_{\mathrm{p}}$, and $d$. The relation between $\Delta L_{\mathrm{AE}}$ and $\phi$ was expressed with $a \log _{10}(3 \phi / 2 \pi(1-b)+b)$ for each $d, H$, and $h_{\mathrm{p}}$, and the regression coefficients were calculated by the least squares method. Coefficients $a$ and $b$ were then expressed with functions of $d, H$, and $h_{\mathrm{p}}$.

Next, the difference between $\Delta L_{\mathrm{AE}}$ and $a \log _{10}(3 \phi / 2 \pi(1-b)+b)$ was expressed by $\Delta L_{\mathrm{AE}, \xi}$ and the relation between $\Delta L_{\mathrm{AE}, \xi}$ and $d, H, h_{\mathrm{p}}$, and $\xi$ were examined. As a result, it was found that $\Delta L_{\mathrm{AE}, \xi}$ decreases as $\xi$ increases as shown in Fig. 7, and any other relations were not distinctly found $[4,5]$. Hence, $\Delta L_{\mathrm{AE}, \xi}$ was firstly expressed with the equation $u \xi+v$, and then regression coefficients $u$ and $v$ were calculated.

\subsection{Empirical Formula}

Thus, an empirical formula to predict excess attenuation of road traffic noise by detached houses was obtained as follows:

$$
\Delta L_{\mathrm{AE}}= \begin{cases}a \log _{10}\left(\frac{3 \phi}{2 \pi}(1-b)+b\right) & (\phi \neq 0) \\ a \log _{10} b+u \xi+v & (\phi=0)\end{cases}
$$

where

$$
\begin{aligned}
& a=p+q \log _{10} d \\
& \quad p=2.03 H-2.63 h_{\mathrm{p}}+4.64 \\
& \quad q=-1.10 H+1.47 h_{\mathrm{p}}-1.21 \\
& b=10^{(s d+t) / a} \\
& \quad s=-0.0023 H-0.009 h_{\mathrm{p}}-0.123 \\
& \quad t=-0.29 H+0.94 h_{\mathrm{p}}-3.74 \\
& u=-20.0 \\
& v=6.59
\end{aligned}
$$



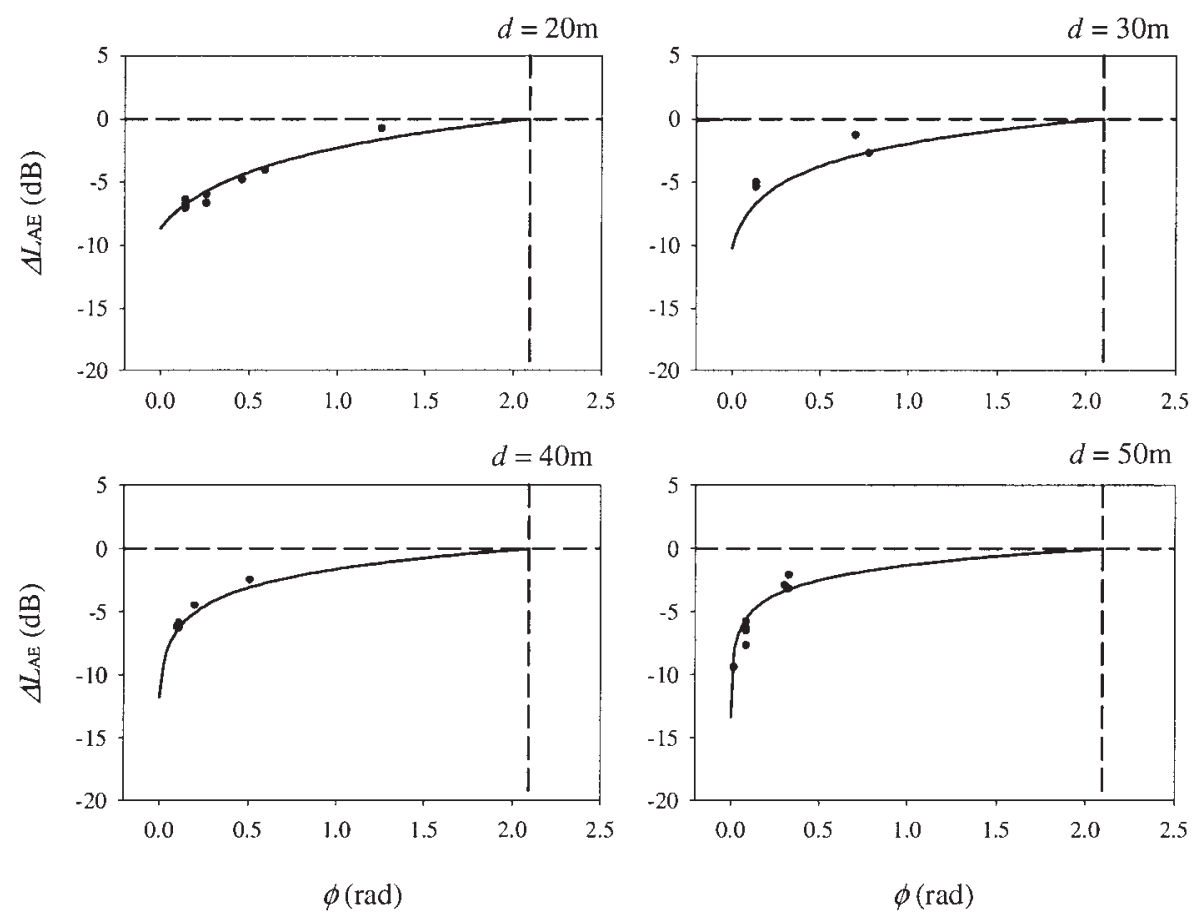

Fig. 6 Relation between $\Delta L_{\mathrm{AE}}$ and $\phi\left(H=10 \mathrm{~m}, h_{\mathrm{p}}=1.2 \mathrm{~m}\right)$.

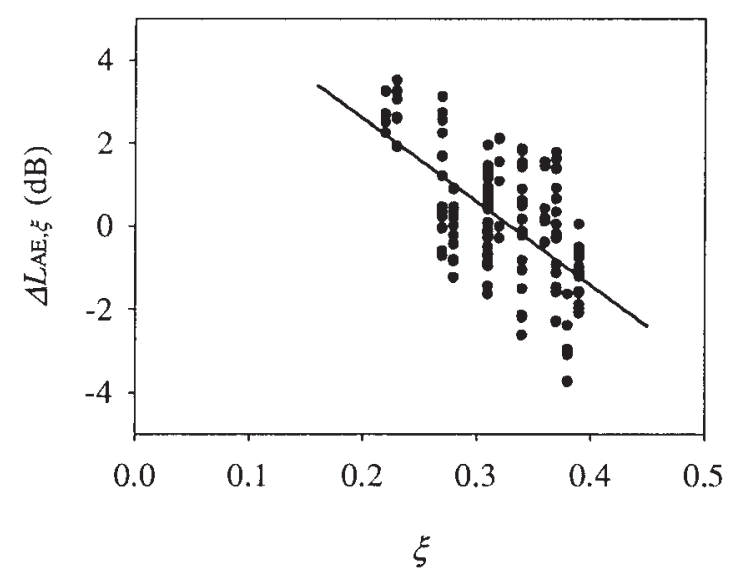

Fig. 7 Relation between $\Delta L_{\mathrm{AE}, \xi}$ and $\xi$.

$\Delta L_{\mathrm{AE}}: \quad$ excess attenuation by detached houses $(\mathrm{dB})$

$\phi: \quad$ open angle (rad)

$\xi:$ house-occupied rate (-)

$d$ : distance between receiving point and road (m)

$H$ : height of houses (m)

$h_{\mathrm{p}}$ : height of receiving point $(\mathrm{m})$.

Due to the experimental conditions, the formula is valid only when $d$ is within $50 \mathrm{~m}$ of the road, $\xi$ is less than $0.4, H$ is within $10 \mathrm{~m}$, and $h_{\mathrm{p}}$ is less than the height of the houses. A comparison between the experimental and the predicted values by Eq. (1) is shown in Fig. 8. The correlation coefficient between them is 0.95 , and the differences between them are within $\pm 3 \mathrm{~dB}$. This proves that the prediction formula has sufficient accuracy.

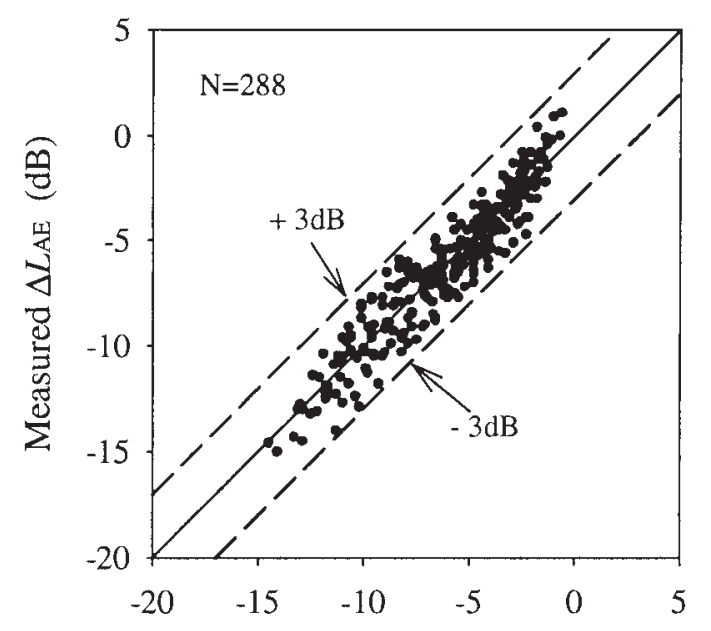

Predicted $\Delta L \mathrm{AE}(\mathrm{dB})$

Fig. 8 Comparison between experimental and predicted values by Eq. (1).

\subsection{Comparison with the Previous Prediction Formula}

Equation (1) was compared with the prediction formula previously proposed by the authors in 2000 [4,5], and is shown in Fig. 9. In the previous formula, the height of the receiving points was limited to only $1.2 \mathrm{~m}$ and the height of the houses was not considered. Thus, on the whole, the previous formula tended to yield intermediate values in comparison to the calculated values using Eq. (1) in which the height of the buildings is now considered as a parameter. Although the influence of the experimental errors is recognized when observing the data in Fig. 9 

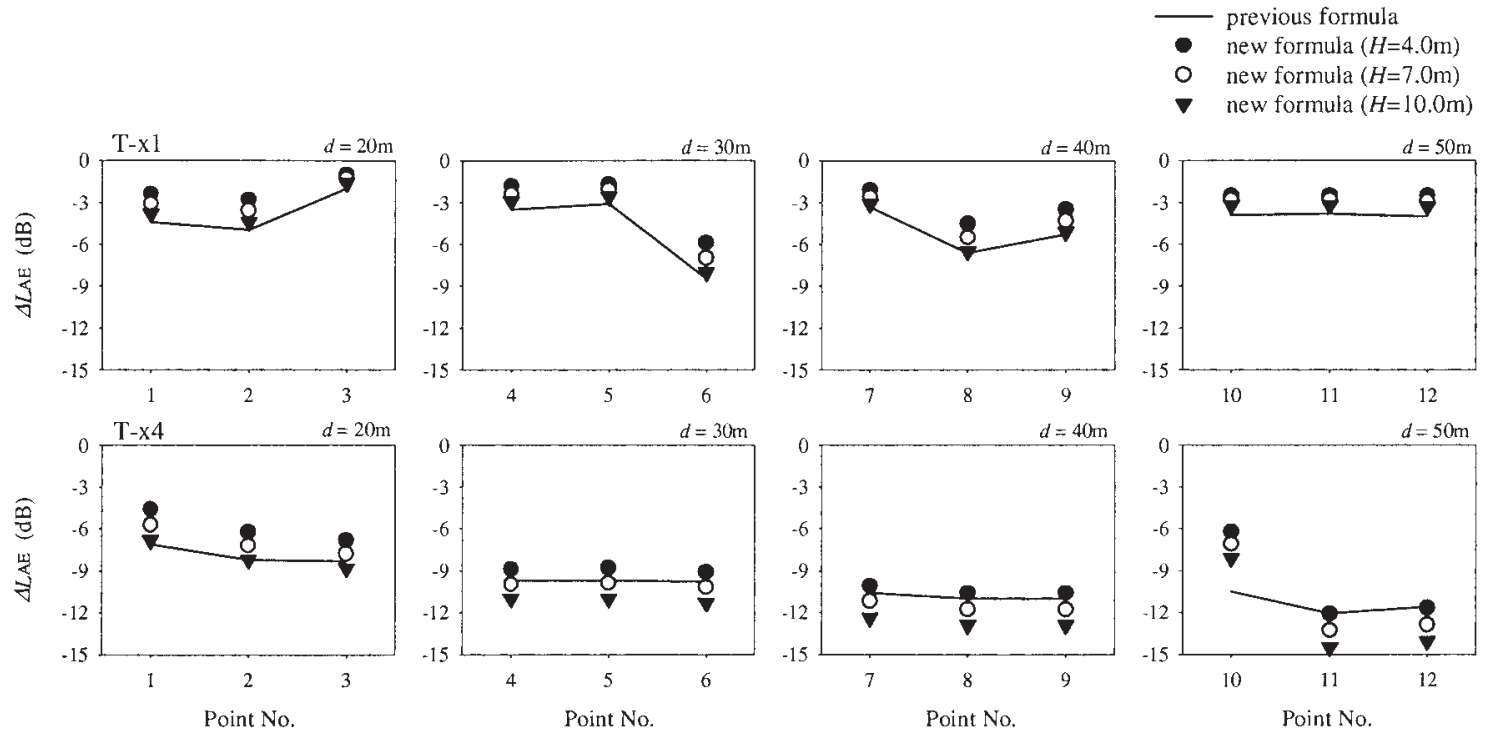

Fig. 9 Comparison between the previous prediction formula and the new formula.

individually, the differences between the calculated values by the previous formula and the values by Eq. (1) are generally less than $\pm 3 \mathrm{~dB}$. It can be concluded, therefore, that Eq. (1) presents almost the same values as the previous formula.

\subsection{Properties of the Prediction Formula}

Figure 10 demonstrates some examples of $\Delta L_{\mathrm{AE}}$ calculated by the prediction formula. It is found that the excess attenuation increases as $h_{\mathrm{p}}$ increases and increases as $H$ decreases at specific receiving points.

\section{EXAMINATION OF THE VALIDITY OF THE PREDICTION FORMULA}

\subsection{Verification by Experiments}

In order to verify the validity of the proposed formula, two kinds of additional model experiments ( $\mathrm{A}$ and $\mathrm{B}$ ) were performed.

In the first experiment (Experiment $\mathrm{A}$ ), the experimental conditions were set to be the same as those in the experiment in Section 2 ('the former experiment') except for $h_{\mathrm{p}}$. The arrangements of the houses in the former experiment, namely, T- $x 1$ and T- $x 3(x=1,2$, and 3$)$, were employed as shown in Fig. 2. $h_{\mathrm{p}}$ was $3.2 \mathrm{~m}$ when $H$ was $4 \mathrm{~m}, 3.2 \mathrm{~m}$ and $6.2 \mathrm{~m}$ when $H$ was $7 \mathrm{~m}$, and $3.2 \mathrm{~m}, 6.2 \mathrm{~m}$, and $9.2 \mathrm{~m}$ when $H$ was $10 \mathrm{~m}$. An example of the comparison between the experimental and the predicted values is shown in Fig. 11. Although the results for only one receiving point among twelve points are shown in Fig. 11 due to limitation of space, other results show a similar tendency. The results show that the differences between them are all within $\pm 3 \mathrm{~dB}$. This verifies that the proposed formula has sufficient accuracy even when $h_{\mathrm{p}}$ is varied.
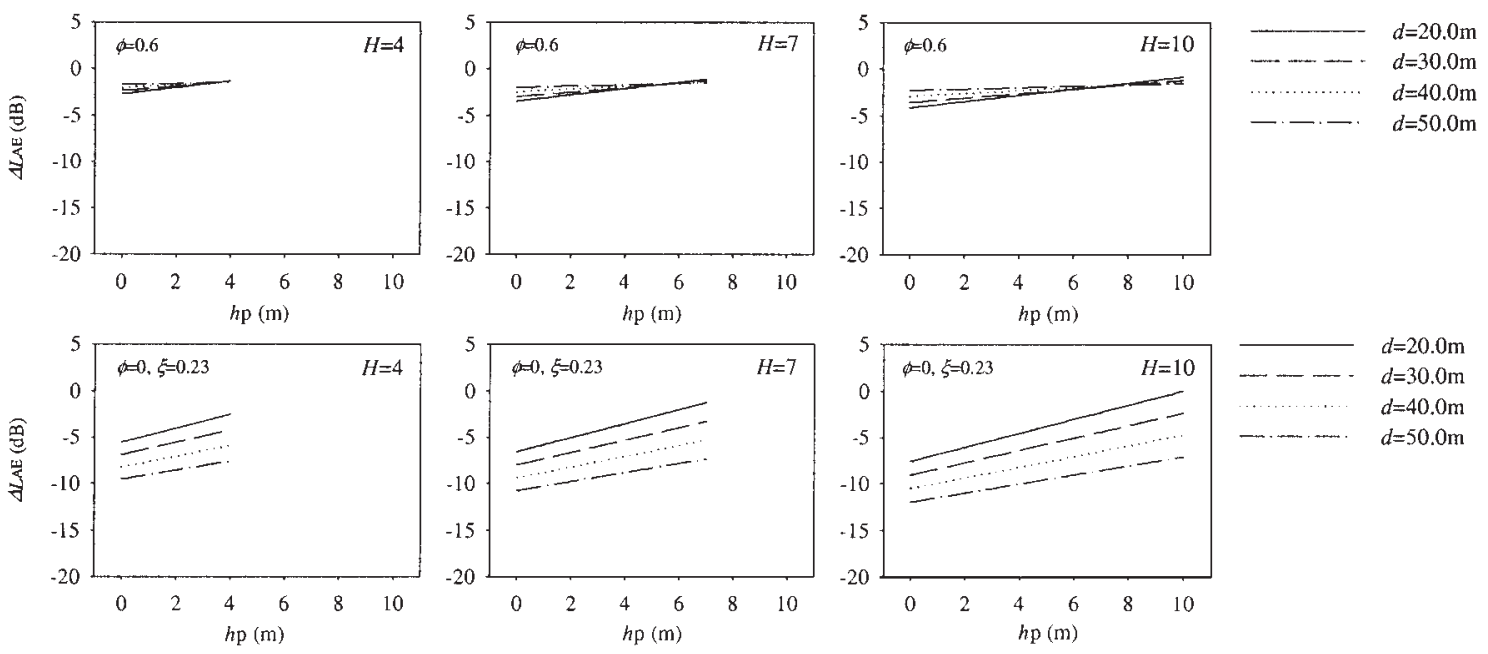

Fig. 10 Properties of the prediction formula. 

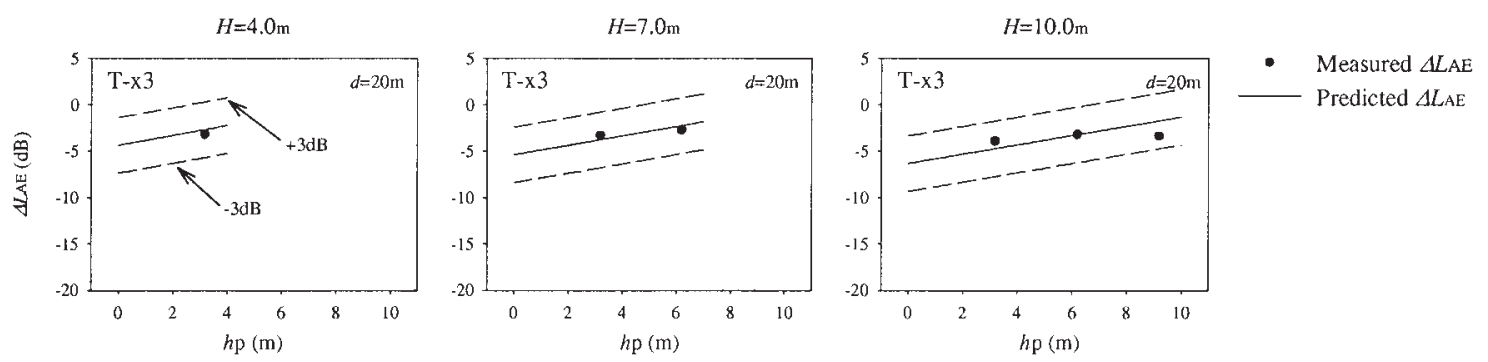

Fig. 11 Comparison between experimental and predicted values (Experiment A, $d=20 \mathrm{~m}$ ).

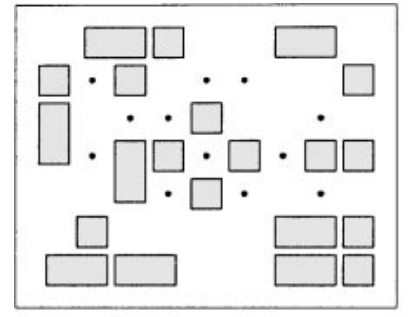

$\mathrm{T}-15,25,35$

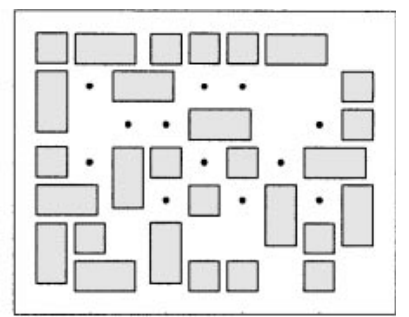

T-18, 28, 38
Fig. 12 Arrangements of model houses (Experiment B).

In the second experiment (Experiment $\mathrm{B}$ ), $h_{\mathrm{p}}$ and the arrangements of the houses were changed. The newly employed arrangements are shown in Fig. 12. The covering percentages were $24.8 \%$ for $\mathrm{T}-x 5(x=1,2$, and 3$)$ and $32.8 \%$ for $\mathrm{T}-x 8(x=1,2$, and 3$)$, which were in the coverage of the prediction formula. The $h_{\mathrm{p}}$ was $1.2 \mathrm{~m}$ and $3.2 \mathrm{~m}$ when $H$ was $4 \mathrm{~m}, 1.2 \mathrm{~m}, 3.2 \mathrm{~m}, 5.2 \mathrm{~m}, 6.2 \mathrm{~m}$, and $7.0 \mathrm{~m}$ when $H$ was $7 \mathrm{~m}$, and $1.2 \mathrm{~m}, 3.2 \mathrm{~m}, 5.2 \mathrm{~m}, 6.2 \mathrm{~m}$, $8.2 \mathrm{~m}$, and $9.2 \mathrm{~m}$ when $H$ was $10 \mathrm{~m}$. An example of the comparison between the experimental and the predicted values is shown in Fig. 13. Although the results for only one receiving point among twenty-four points (in two patterns) are shown in Fig. 13 due to limitation of space, other results show a similar tendency. As a result of the examination, the differences between them were roughly within $\pm 3 \mathrm{~dB}$. This shows that sufficient accuracy was maintained, although the level of accuracy was slightly lower than that for Experiment A. It was also verified that the formula has sufficient accuracy even when both $h_{\mathrm{p}}$ and the arrangements of the houses are varied.

\subsection{The ASJ Model 1998}

The prediction formula proposed here was compared with the method for predicting the attenuation by buildings shown in the ASJ Model 1998. The arrangements of the houses shown in Fig. 2, namely, T- $x 1, \mathrm{~T}-x 2, \mathrm{~T}-x 3$, and T- $x 4$ ( $x=1,2$, and 3 ), were used for the comparison. The ASJ Model 1998 was used to predict the 'average' value in the evaluating area; and consequently, it represented the same value when the distance from the road was constant. On the other hand, the proposed formula predicted the attenuation at specific points. For the comparison, the attenuation at point intervals of $1 \mathrm{~m}$ on seven lines (from $20 \mathrm{~m}$ to $50 \mathrm{~m}$ at intervals of $5 \mathrm{~m}$ ) parallel to the road were calculated by Eq. (1). Then, the arithmetic average value for each line was compared with the value predicted by the ASJ Model 1998. An example of the results is shown in Fig. 14. Compared with the ASJ Model 1998, Eq. (1) represents slightly lower values when the receiving points are off the road, but the differences between them are small.

As mentioned above, the prediction formula provides an individual value for each predicting point, while the ASJ Model 1998 only provides an average value for the entire target area. The degree of agreement between them strongly depends on the arrangement of the houses. Therefore, Fig. 14 implies that Eq. (1) yields, on the whole, almost the same or lower values compared with the method of the ASJ Model 1998.

\subsection{Noise Measurements in Actual Residential Areas}

Road traffic noise was measured in two actual residential areas and was compared with the predicted
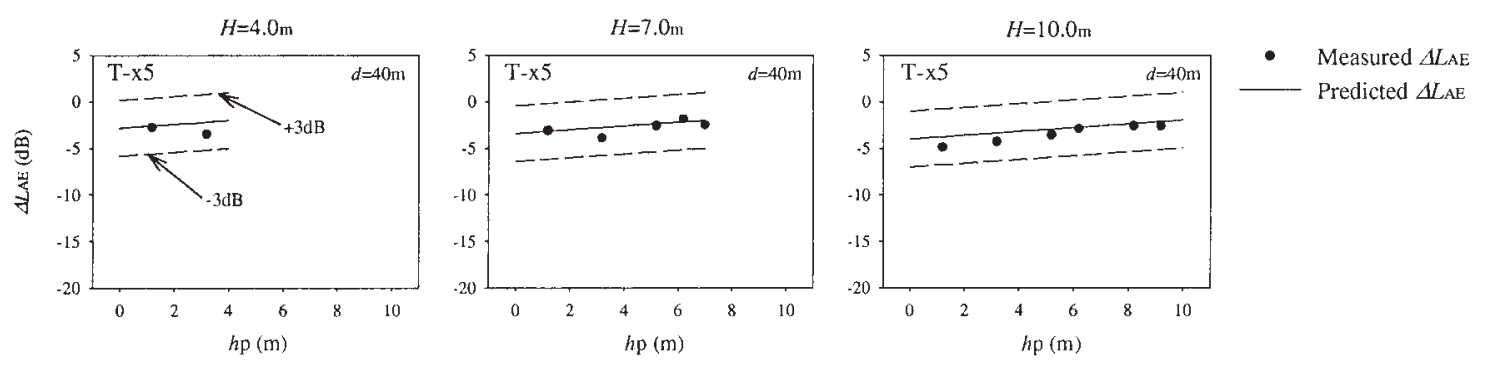

Fig. 13 Comparison between experimental and predicted values (Experiment B, $d=40 \mathrm{~m}$ ). 


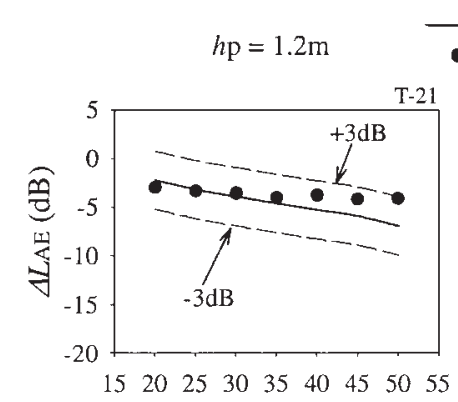

ILAE based on the ASJ Model 1998

- $\triangle L A E$ based on the empirical formula
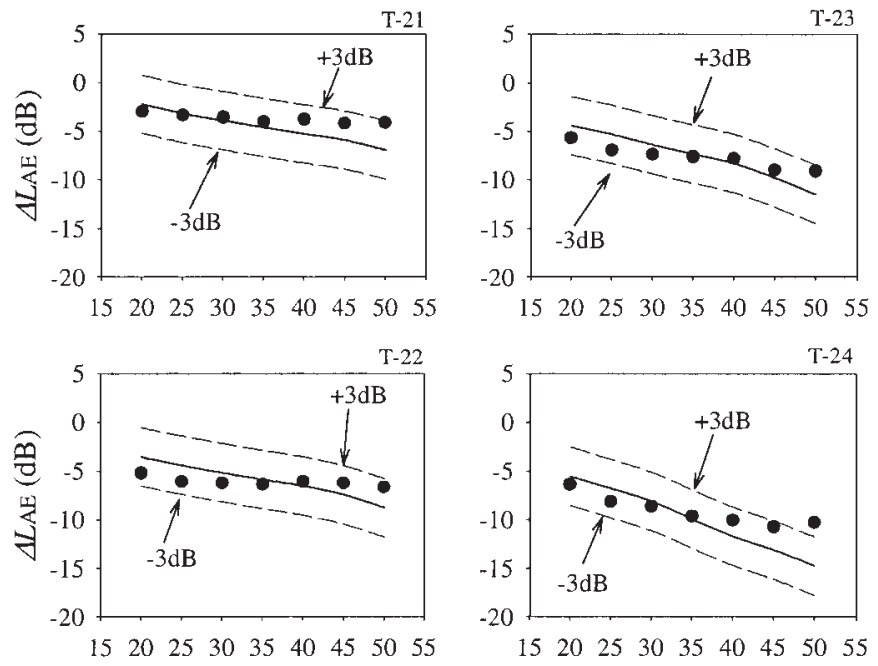

$d(\mathrm{~m})$

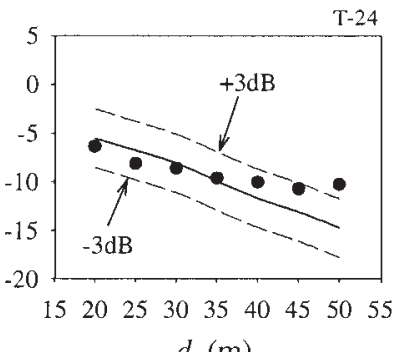

$d(\mathrm{~m})$

Fig. 14 Comparison between the ASJ Model 1998 and the prediction formula.

values calculated by Eq. (1). The two areas (A and B) were selected along roads with heavy traffic in Fukuoka City. An outline of the areas is shown in Table 1, and the arrangements of the houses in both areas are shown in Fig. 15. The number of traffic lanes was four for area $\mathrm{A}$ and two for area B, and the width of the roads was $20 \mathrm{~m}$ for area $\mathrm{A}$ and $10 \mathrm{~m}$ for area B. Almost all of the houses located there were two-story detached houses. The values for noise level $L_{\mathrm{Aeq}}$ by the roadside were approximately $69 \mathrm{~dB}$ to $81 \mathrm{~dB}$.

In order to obtain the excess attenuation by the houses, $L_{\text {Aeq,20s }}$ was measured simultaneously at points by the roadside and in the residential areas. The number of measuring points by the roadside was two for area A and three for area B. The number of measuring points in the residential areas was fifteen for area A $\left(9: h_{\mathrm{p}}=1.2 \mathrm{~m}\right.$ and 6: $\left.h_{\mathrm{p}}=5.2 \mathrm{~m}\right)$ and twelve for area B $\left(9: h_{\mathrm{p}}=1.2 \mathrm{~m}\right.$ and 3: $\left.h_{\mathrm{p}}=5.2 \mathrm{~m}\right)$. The distances from the measuring points to the road were from $30 \mathrm{~m}$ to $68 \mathrm{~m}, \phi$ was from 0.0 to 1.24 , and $\xi$ was from 0.13 to 0.31 . Thus, the measuring points fulfilled the conditions of the prediction formula.

Excess attenuation $\Delta L_{\mathrm{AE}}$ was calculated by the

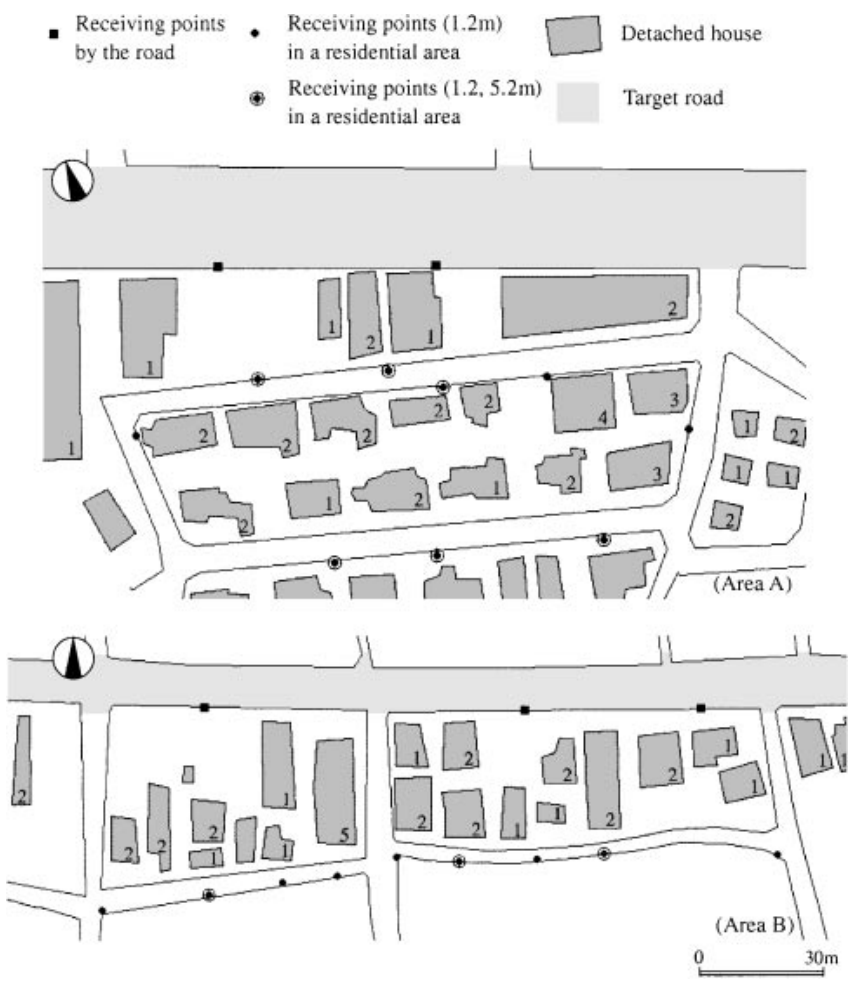

Fig. 15 Arrangements of houses in two actual areas.

following formula, namely, $\Delta L_{\mathrm{AE}}=L_{\mathrm{AE}, d}-L_{\mathrm{AE}, d_{0}}+$ $10 \log _{10}\left(d / d_{0}\right)$, for which $L_{\mathrm{AE}, d}$ was the measured value in the residential area and $L_{\mathrm{AE}, d_{0}}$ was the measured value by the roadside, and $d_{0}$ and $d$ were the distances between the measuring points by the roadside and in the residential areas and the center of the road, respectively. Figure 16 shows a comparison between the measured and the predicted values using Eq. (1). The differences between them were within $\pm 5 \mathrm{~dB}$ when $h_{\mathrm{p}}$ was $1.2 \mathrm{~m}$ and within $\pm 3 \mathrm{~dB}$ when $h_{\mathrm{p}}$ was $5.2 \mathrm{~m}$. On the whole, they are in good agreement. It can be guessed that the measured values tended to be moderately lower than the predicted ones when $h_{\mathrm{p}}$ was $1.2 \mathrm{~m}$, because guardrails, walls, and/or garden plants are not typically drawn on maps.

\subsection{Comparison with the Survey Data by the Ministry of Land, Infrastructure and Transport}

Uesaka et al. [7] reported many data on the excess attenuation of road traffic noise by houses which were

Table 1 Outline of the noise measurements in two actual areas.

\begin{tabular}{|c|c|c|c|c|c|c|c|c|c|}
\hline \multirow[b]{2}{*}{ Areas } & \multirow[b]{2}{*}{$\begin{array}{l}\text { Numbers } \\
\text { of points }\end{array}$} & \multicolumn{2}{|c|}{ Outline of roads } & \multirow[b]{2}{*}{$\begin{array}{c}\text { Noise level } \\
\text { at roadside } \\
L_{\text {Aeq }}(\mathrm{dB})\end{array}$} & \multirow[b]{2}{*}{$\phi(\mathrm{rad})$} & \multirow[b]{2}{*}{$\xi$} & \multirow[b]{2}{*}{$d(\mathrm{~m})$} & \multirow[b]{2}{*}{$H(\mathrm{~m})$} & \multirow[b]{2}{*}{$h_{\mathrm{p}}(\mathrm{m})$} \\
\hline & & $\begin{array}{l}\text { Number } \\
\text { of lanes }\end{array}$ & $\begin{array}{l}\text { Width of } \\
\text { roads }(m)\end{array}$ & & & & & & \\
\hline A & $\begin{array}{l}9 \\
6\end{array}$ & 4 & 20.0 & $68.7-80.7$ & $0.0-1.24$ & $0.13-0.30$ & $30-68$ & 5.9 & $\begin{array}{l}1.2 \\
5.2\end{array}$ \\
\hline B & $\begin{array}{l}9 \\
3\end{array}$ & 2 & 10.0 & $70.0-78.7$ & $0.0-0.40$ & $\begin{array}{l}0.24-0.31 \\
0.27-0.31\end{array}$ & $\begin{array}{l}34-49 \\
36-45\end{array}$ & 9.5 & $\begin{array}{l}1.2 \\
5.2\end{array}$ \\
\hline
\end{tabular}




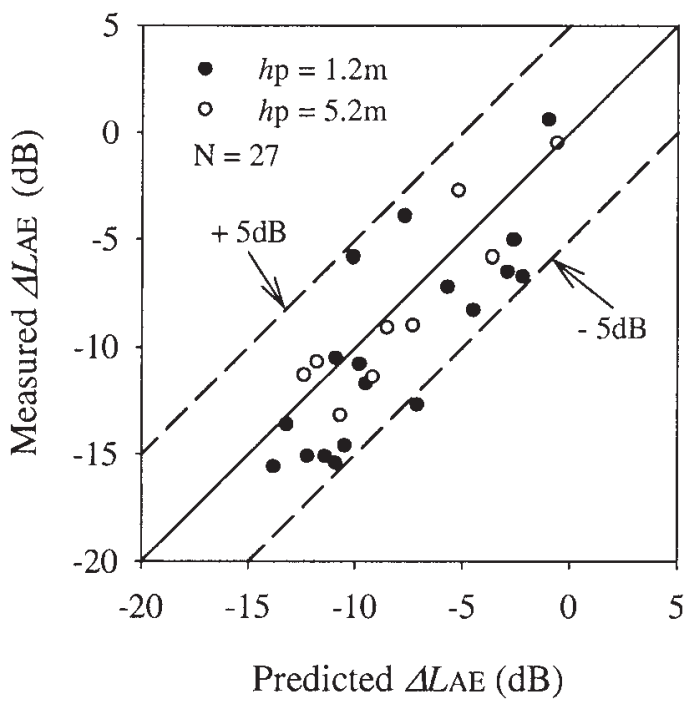

Fig. 16 Comparison between measured and predicted values in an actual area by Eq. (1).

measured by local governments throughout the country under the guidance of the Ministry of Land, Infrastructure and Transport. The data were compared with the predicted values by Eq. (1). Eight residential areas where detached houses are located were randomly selected from thirtythree areas published in this report.

The five parameters $\left(\phi, \xi, d, H\right.$, and $\left.h_{\mathrm{p}}\right)$, which are necessary for calculating Eq. (1), were read from the attached map. Here, the $\phi$ were between 0.0 and 0.35 and the $\xi$ were between 0.12 and 0.35 ; this fulfilled the conditions of the prediction formula. In addition, the power levels of the acoustic line source were adjusted so that the predicted noise levels at the roadside gave the same values as the measured ones.

Figure 17 presents two examples of a comparison in which the black dots show the measured values at each measuring point, the solid lines show the predicted values by the ASJ Model 1998, and the white circles are the predicted values by Eq. (1). In general, the predicted values by Eq. (1) were slightly higher than the measured values, in

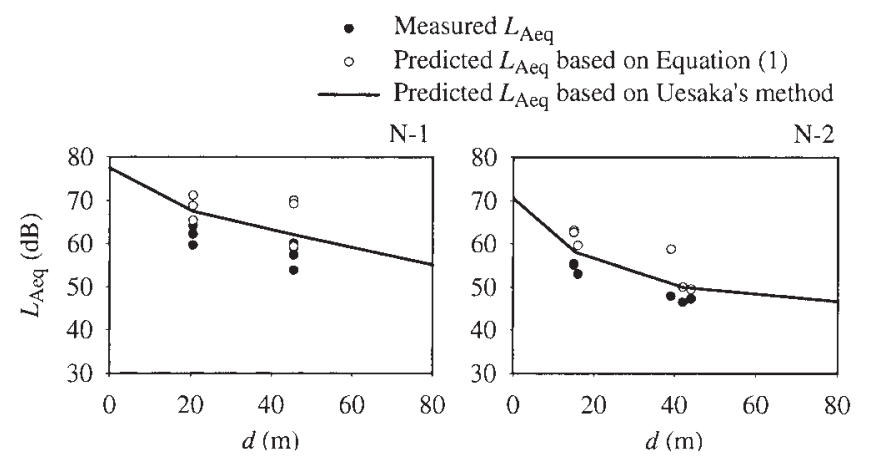

Fig. 17 Comparison between measured and predicted values by the Ministry of Land, Infrastructure and Transport by Eq. (1). other words, the noise levels did not decrease, but the spatially-averaged values at a distance from the road seem to have approached the calculated values by the ASJ Model 1998. It can eventually be said that the prediction formula moderately agrees with the ASJ Model 1998.

\section{APPLICATION OF THE PREDICTION FORMULA}

In order to confirm the application of the prediction formula, simulations of the noise level distribution in a residential area were performed. The arrangement of the houses in the former experiment, T-32 $(H=10 \mathrm{~m})$, was used for the simulation. Figure 18 shows some examples of the noise distribution. In the ground plan, the height of the receiving points is $1.2 \mathrm{~m}$. Here, noise level $L_{\mathrm{pA}}$ at the point with a distance $d$ from the center of the road was calculated by the equation $L_{\mathrm{pA}}=L_{\mathrm{WA}}-8-10 \log _{10} d+\Delta L_{\mathrm{AE}}+$ $\Delta L_{\mathrm{g}}$, where $L_{\mathrm{WA}}$ showed the A-weighted sound power level of the road traffic noise $(\mathrm{dB} / \mathrm{m})$ and $\Delta L_{\mathrm{g}}$ was the compensation for the effect by the ground surface. That is, $L_{\mathrm{pA}}$ showed the relative level by substituting $0 \mathrm{~dB} / \mathrm{m}$ for $L_{\mathrm{WA}}$ and $3 \mathrm{~dB}$ for $\Delta L_{\mathrm{g}}$, as a semi-free sound field. Since Eq. (1) can predict excess attenuation at arbitrary points which are lower than the houses, the noise level distribution for the fixed height as well as for the perpendicular direction could be grasped.

Figure 19 presents an example of the noise distribution when the houses were not randomly arranged. In this simulation, the height of the houses was $7 \mathrm{~m}$ and the height of the receiving points was $1.2 \mathrm{~m}$. The equal $L_{\mathrm{pA}}$ contour lines calculated by the ASJ Model 1998 were parallel to the road in the plane distribution chart. On the other hand, the prediction formula provided a reasonable noise distribution corresponding to the arranged houses, because it can predict an individual value for each predicting point. In particular, in the zone with a wide view of the road, a remarkable difference was recognized between them.

\section{CONCLUSION}

A one-twentieth scale model experiment was performed and a simple method for predicting the excess attenuation of road traffic noise by detached houses was proposed. This method can predict excess attenuation at arbitrary points below the height of the houses. The validity and the accuracy of the proposed formula were verified by two additional experiments, a comparison with the ASJ Model 1998, and noise measurements taken at actual residential areas. It was shown that the proposed formula can indeed provide a distribution of noise levels that corresponds to the arranged houses. Since the five parameters used in the formula, namely, the open angle $(\phi)$, the house-occupied rate $(\xi)$, the distance between a receiving point and the road $(d)$, the height of the houses 

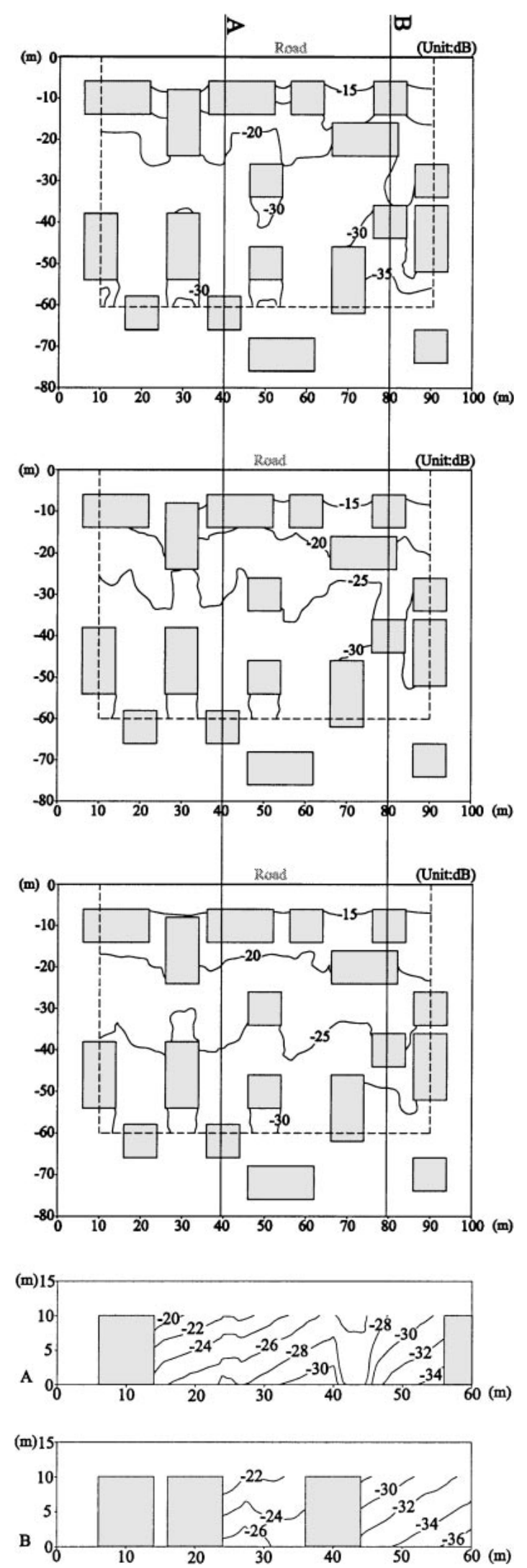

Fig. 18 Examples of noise distribution in consideration of the excess attenuation by houses $\left(h_{\mathrm{p}}=1.2 \mathrm{~m}, 5.2 \mathrm{~m}\right.$, and $8.2 \mathrm{~m}$, respectively, in order from top to bottom charts).

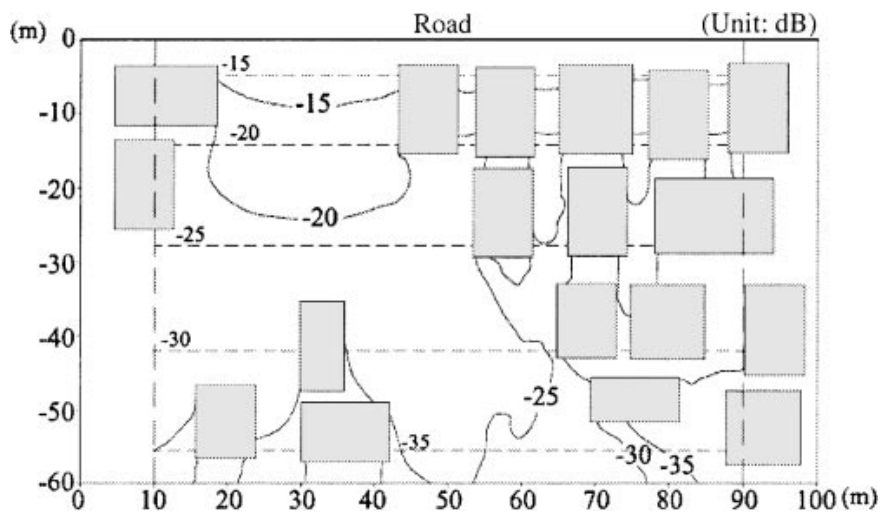

Fig. 19 Comparison between the ASJ Model 1998 and the prediction formula $\left(h_{\mathrm{p}}=1.2 \mathrm{~m}\right)$.

$(H)$, and the height of a receiving point $\left(h_{\mathrm{p}}\right)$, can easily be determined at the beginning stages of the planning of residential areas, the formula can be applied to the planning of housing arrangements in residential areas by considering the effect of road traffic noise.

\section{ACKNOWLEDGMENTS}

The authors wish to thank Mr. Kataoka and Mr. Nishimura, former students of Kyushu University, for their help with the experiments and the analyses. The authors are also grateful to Asia Air Survey Co., Ltd. and to Dr. Muraji of EnergySharing Co., Ltd. for cooperating with the surveying of the road traffic noise. The authors feel deep appreciation toward Dr. Uesaka of the Ministry of Land, Infrastructure and Transport, for allowing the use of survey data quotations.

\section{REFERENCES}

[1] Notification No. 64 of the Environmental Agency in Japan, "Environmental quality standards for noise" (1998).

[2] K. Uesaka, H. Ohnishi, T. Miyake and K. Takagi, "Simple methods for calculating $L_{\mathrm{Aeq}}$ behind a building and a row of buildings directly facing a road," $J$. INCE/J, 23, 441-451 (1999).

[3] Research Committee of Road Traffic Noise in the Acoustical Society of Japan, "ASJ prediction model 1998 for road traffic noise," J. Acoust. Soc. Jpn. (J), 55, 281-324 (1999).

[4] K. Fujimoto, K. Yasunaga, K. Esaki and H. Ohmori, "Attenuation of road traffic noise by detached houses," J. Acoust. Soc. Jpn. (J), 56, 815-824 (2000).

[5] K. Fujimoto, K. Esaki and H. Ohmori, "Level attenuation of road traffic noise by the detached houses," Proc. 7th Western Pacific Regional Acoustics Conf., Vol. 125, pp. 1-4 (2000).

[6] T. Sone, S. Kono and T. Iwase, "Power levels and their spectra of automobile noise," J. Acoust. Soc. Jpn. (J), 50, 233-239 (1994).

[7] K. Uesaka, K. Kimura, Y. Namikawa and H. Ohnishi, "Study on calculation and evaluation method of road traffic noise in a roadside built-up area," Technical Note of National Institute for Land and Infrastructure Management, No. 2 (2001). 


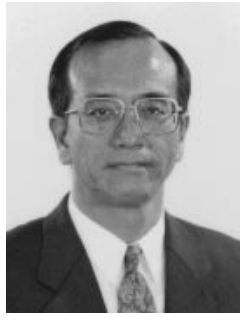

Kazutoshi Fujimoto graduated from Kyushu University in 1972 and received Dr. Eng. degree from Kyushu University in 1986. He is now a professor at Department of Architecture and Urban Design, Kyushu University, Japan. His research interests include prediction and evaluation of road traffic noise, acoustical design of concert hall and soundscape study. $\mathrm{He}$ is a member of Acoustical Society of Japan, Architectural Institute of Japan, Institute of Noise Control Engineering Japan and Soundscape Association of Japan.

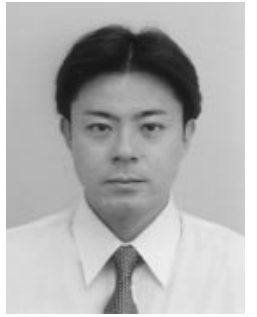

Ken Anai received the Dr. Eng. degree from Kyushu University, Japan in 2000. He is currently a research associate of Department of Architecture and Urban Design, Kyushu University. His research field is the architectural environment. $\mathrm{He}$ is a member of the ASJ, Architectural Institute of Japan, Illuminating Engineering Institute of Japan and Japanese National Committee of CIE.

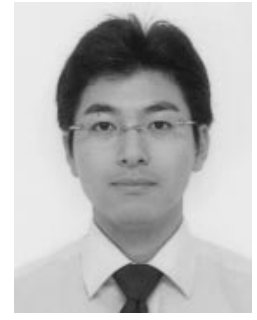

Ryusei Ohta graduated from Kyushu University in 2000. The Society of Heating, AirConditioning and Sanitary Engineers of Japan conferred him the Award of Promotion (Student Award). On receiving master degree from Kyushu University, he was awarded the dean prize from the Graduate School of Human2002.
Environment Studies of Kyushu University in 